\title{
Performance Evaluation of Vegetable Washer for Carrot Crop
}

\author{
Narender $^{1 *}$, S. Mukesh ${ }^{2}$, Vijaya Rani², Anil Kumar², \\ Kanishk Verma ${ }^{3}$ and Nitin Karwasra ${ }^{3}$ \\ ${ }^{1}$ Department of FMPE, College of Agricultural Engineering, JNKVV Jabalpur, \\ MP-482004, India \\ ${ }^{2}$ Department of FMPE, College of Agricultural Engineering and Technology, CCS HAU, \\ Hissar, HR-125004, India \\ ${ }^{3}$ Department of FMPE, College of Agricultural Engineering and Technology, PAU, \\ Ludhiana-141004, Punjab, India \\ *Corresponding author
}

\begin{abstract}
A B S T R A C T
Keywords

Mechanical washing efficiency, Microbial efficiency and bruising percentage, Carrot

Article Info

Accepted:

06 December 2017

Available Online:

10 January 2018

The vegetable crop especially root crop must be washed before the transportation from field to market. For a small scale farmer, it is a labour consuming process. A vegetable washing machine was evaluated for carrot crop. The performance parameters of machine such as mechanical washing efficiency, microbial efficiency and bruising percentage were determined. The speed of the rotor drum was $25 \mathrm{rpm}$. The performance results showed that the mechanical washing efficiency, microbial efficiency and bruising percentage were varied from 72.80 to $78 \%, 88$ to $92 \%$ and 5.80 to $8.50 \%$, respectively. The fuel consumption was found to be 1.8 to $2.21 \mathrm{~h}^{-1}$.

\section{Introduction}

India is the second largest producer of vegetable in world. Total production of vegetable in India is 169064 thousand metric tonnes in an area of 10106 thousand hectares during the year 2015-16. Fresh vegetables are important component of the human diet. In vegetable crops, the production of carrot was 1338 thousand metric tonnes in an area of 82 thousand hectare. The percentage share of Haryana state in production of carrot crop was

27.41 (NHB, 2014-15). To avoid spoilage of vegetables they must be washed after harvesting from the field. They need to be precleaned before transporting from field to market. Washing carrots is necessary to remove soil and other foreign material before sorting, grading, weighing and selling in the market. Presently the grower brings the produce to the market, either unwashed or inadequately washed under unsanitary conditions (washed with dirty feet and hands using polluted water from ponds, drains,
\end{abstract}


streams etc.). This adversely affects the quality of the produce, which leads to reduced profits and shelf life. Prevention of contamination is the most efficient way to ensure food safety and prevent foodborne illness. Thus, every effort should be made to protect food from primary sources of contamination. Vegetables are washed in fields using a water jet delivered from a hosepipe and immersion soaking.

These methods demand more labour but washing efficiency is very low due to nonremoval of thin layer of surface mud coating. So there is a need for and efficient washer to remove the mud and other foreign matter present on the surface of the vegetables, more specifically for root crops. Vegetables are washed thoroughly to remove particles of soil and micro-organisms that are present in soil. Washing of vegetables can be done manually or mechanically. Manual washing of vegetables are very time and labour consuming process. The problem of labour availability is much more at present time.

The use of continuous type vegetable washing machine can be used for washing carrot, ginger (adarak), colocasia (arbi) and turmeric (haldi) which can reduce the labour requirement and is also a time saving method of washing of vegetables. Washing of vegetables generally reduces the microbial load by $100-1000$ fold. This prevents pathogens from being transferred from the rind or skin to the inside of the fruit or vegetable when it is cut (Laanen and Scott, 2004). To prevent spoilage and mold growth during storage, it is necessary to wash fresh vegetables. Hence, the present study was undertaken to develop a vegetable washing machine for adequate washing of vegetables. This machine is a tractor trailed type PTO driven machine which is tested for carrot crop and could also be run on stationary diesel engine which is supplied as optional feature.

\section{Materials and Methods}

The vegetable washing machine consists of a rotor which runs at $25 \mathrm{rpm}$ approximately. The rotating drum is made of 197 nos. of square MS bars of $0.7 \times 0.7 \mathrm{~cm}$ size on the periphery of drum of diameter $91 \mathrm{~cm}$.

The length of the drum is $3.60 \mathrm{~m}$ and mounted between two bearings fixed on the frame through a hallow shaft of diameter $5.7 \mathrm{~cm}$. Stainless steel pipe carrying water is mounted on one side of the rotating drum.

A centrifugal pump is used for spraying water through pipe on the carrot in the drum so that the carrots are cleaned. Power input shaft receives drive from tractor PTO shaft and transmits power to centrifugal pump and rotor assembly through V-belt and pulley and set of gears.

Rotating parts and moving belts are covered with guard for operational safety. From one end of the rotor, the vegetable is fed through the feeding chute of size $825 \times 770 \times 120 \mathrm{~mm}$ with an inclination of $24^{0}$ towards inlet and allowed to travel the entire length of the drum i.e. $3.60 \mathrm{~m}$ and thus the carrot gets cleaned up as it reaches the outlet. To evaluate the mechanical washing efficiency, microbial washing efficiency and bruise percentage of continuous type carrot washer, experimental test were conducted at Behabalpur, Hisar following the standard procedure:

\section{Performance parameters of vegetable washer}

The machine was evaluated at a different feed rate of carrot for a speed of rotor drum of 25 rpm (Sehgal and Arora, 2006). The performance of the washer was evaluated based on the mechanical washing efficiency, microbial efficiency and bruising percentage as per the procedure mentioned below: 


\section{Mechanical washing efficiency}

The mechanical washing efficiency of machine was determine as the ratio of the difference of weight of carrots before and after washing to the weight before washing on the percentage basis.

Mechanical washing efficiency, \%

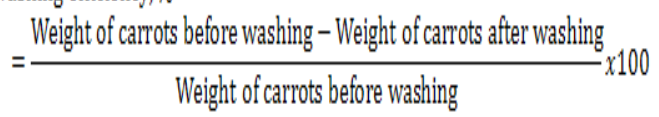

\section{The microbial washing efficiency}

The surface microbial load in terms of total plate count (colony forming units, cfu) before and after washing of carrot was determined by serial dilution technique as enumerated by Ranganna (1986). The microbial washing efficiency was calculated as follows (Arora $e t$ al., 2007)

Microbial washing eficiciency $=\frac{\text { Initial microbial load }- \text { Final microbial load }}{\text { Initial microbial load }} \times 100$

\section{Bruising percentage}

Bruised carrot required to know the percentage of bruised carrots (skin comes cut) either by striking with carrot itself or due to rubbing action while being conveyed on the revolving drum. It was defined as follows:

Bruising percentage $=\frac{\text { Weight of bruised carrots after washing }}{\text { Total Weight of carrots after washing }} x 100$

\section{Retention time}

For determination of retention time, marked sample of carrot and was fed in the hopper with other carrot.

The sample carrot was allowed to travel the entire length of the drum.

The time it remained inside the drum was noted which is the retention time of carrot crop inside the revolving drum.

\section{Results and Discussion}

Field test of vegetable washing machine was conducted for carrot crop at Village Behbalpur, District Hisar (Haryana) for 20 hours consisting of 4 trials. The detailed test results are given in Table 1 and the optimum performance parameters for vegetable washing machine are in summarized in Table 2.

Table.1 Performance of vegetable washing machine under different test

\begin{tabular}{|l|l|c|c|c|c|}
\hline S. No. & Test & 1 & 2 & 3 & 4 \\
\hline 1. & Duration of test (h) & 4.5 & 5.0 & 5.5 & 5.0 \\
\hline 2. & Feed rate $\left(\mathrm{kg} \mathrm{h}^{-1}\right)$ & 2480 & 2530 & 2660 & 2720 \\
\hline 3. & Retention time, minutes & 4.0 & 4.5 & 4.5 & 5.0 \\
\hline 4. & Mechanical washing efficiency, \% & 72.5 & 74.0 & 75.6 & 78.0 \\
\hline 5. & Microbial washing efficiency, \% & 92 & 90 & 90 & 88 \\
\hline 6. & Bruising percentage, \% & 6.76 & 5.80 & 7.25 & 8.50 \\
\hline 7. & Speed of rotor drum & 25 & 25 & 25 & 25 \\
\hline
\end{tabular}


Table.2 Optimum performance parameters for vegetable washing machine

\begin{tabular}{|l|l|l|}
\hline S. No. & Parameters & Range of measurement \\
\hline 1. & Feed rate, $\mathrm{kg} \mathrm{h}^{-1}$ & 2480 to 2720 \\
\hline 2. & Retention time, minutes & 4 to 5 \\
\hline 3. & Mechanical Washing Efficiency, \% & 72.50 to 78.00 \\
\hline 4. & Microbial Washing Efficiency, \% & 88 to 92 \\
\hline 5. & Bruising Efficiency, $\%$ & 5.80 to 8.50 \\
\hline 6. & Speed of rotor drum, rpm & 25 \\
\hline 7. & Fuel consumption, $1 \mathrm{~h}^{-1}$ & 1.8 to 2.2 \\
\hline 8. & Labour requirement & Three \\
\hline
\end{tabular}

Fig.1 Influence of retention time on mechanical and microbial washing efficiency

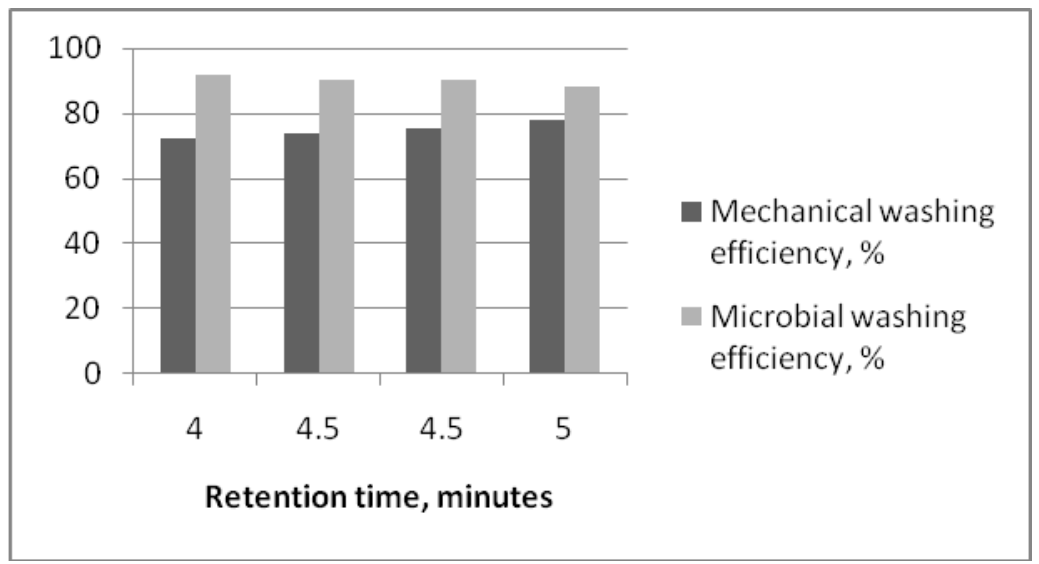

The maximum washing efficiency $(78 \%)$ was achieved at 5 minute of retention time, with $8.5 \%$ bruising to carrot. This may be due to the reason that more retention time results more rubbing action of carrot, which results increase in washing efficiency and bruising percentage. Increase in the feed rate results in more bruising percentage, but washing efficiency was increased (78\%).

From Figure 1, it can also be seen that as the retention time increased from 4 to 5 minute, the mechanical washing efficiency was increased from $72.80 \%$ to $78 \%$ but the microbial washing efficiency was decreased from $92 \%$ to $88 \%$.Similar trends of increase in the mechanical washing efficiency have been reported by Jayashree and Vishvanathan (2010).
The result shows that the machine could be washed the carrot crop. The machine could also be used for the other root crops also such as potato, ginger, turmeric, sweet potato. The optimum operating parameters of carrot washer were the average mechanical washing 75 and operating speed of rotor drum was 25 and the microbial washing efficiency, mechanical washing efficiency and bruising percentage was $90 \%, 75 \%$ and $7 \%$, respectively.

\section{References}

Arora, M., Seghal V.K., Sharma S.R. 2007. Quality evaluation of mechanically washed and polished turmeric rhizomes. Journal of Agricultural Engineering. 44(2): 39-43. 
http://www.nhb.gov.in

Jayashree, E., and Visvanathan R. 2010. Studies on mechanical washing of ginger rhizomes. Journal of Agricultural Engineering. 47(4): 37-40.

Laanen, P.V., and Scott A.2004. Washing fresh fruit and vegetables. Tri-state fruit and vegetable consortium (http://www.fruit and vegetable safety. Tamu.edu).
Ranganna, S., 1986. Hand book of Analysis and Quality control for fruit and vegetable products. Tata McGraw Hills Publication co. Ltd, New Delhi.

Sehgal, V.K., and Arora, M. 2006. Development of a Farm Level Vegetable Washing Machine. Journal of Agricultural Engineering. 43(4): 75-78.

\section{How to cite this article:}

Narender, S. Mukesh, Vijaya Rani, Anil Kumar, Kanishk Verma and Nitin Karwasra. 2018. Performance Evaluation of Vegetable Washer for Carrot Crop. Int.J.Curr.Microbiol.App.Sci. 7(01): 454-458. doi: https://doi.org/10.20546/ijcmas.2018.701.053 